\title{
Capdepón Verdú, P. y Pastor Comín, J. J. (Eds.) (2016). Mozart en España. Estudios y recepción musical. Vigo: Editorial Academia del Hispanismo, 292 pp.
}

¿Qué tienen en común un fandango, el descubrimiento en 2010 de una partitura manuscrita en la Biblioteca de Cataluña, la publicidad de un diario de Madrid de la última década del siglo XVIII, la gira mexicana del tenor y compositor español Manuel García, el Noucentisme catalán, una revista espiritista de 1870 y una película de Joselito? La respuesta en tres palabras: Mozart en España.

El fandango es la danza que Mozart emplea en Le nozze di Figaro para dotar de colorido local a una escena festiva. La partitura descubierta en la Biblioteca de Cataluña en el año 2010 se corresponde con el manuscrito empleado en el estreno español de Cosi fan tutte (Barcelona, 1798). El "Diario de Madrid" del 23 de mayo de 1791 contiene el primer anuncio explícito sobre la venta de partituras de W. A. Mozart. El tenor y compositor español Manuel García difunde las óperas de Mozart en España y en las ciudades de otros cinco países más: París, Nápoles, Londres, Nueva York y Ciudad de México, siendo esta última en donde interpretó Il barbiere di Siviglia y Don Giovanni. Gracias al Noucentisme catalán, que impulsa ideas de transparencia clásica en las primeras décadas del siglo XX, la música de Mozart regresa a escena en los programas de concierto de Barcelona. La "Revista Espiritista" de junio de 1870 publica la conversación que dos médiums habían tenido con el espíritu de Mozart, y que anteriormente Allan Kardec había hecho pública en mayo de 1858. El pequeño coronel (Antonio del Amo, 1960) es una película ideológicamente cercana al régimen franquista en la que la música de Mozart, interpretada por Joselito, representa la música conservadora frente al flamenco, la música del pueblo que debía ser valorada.

Todas estas curiosidades, entre otras muchas más, las encontramos en un libro novedoso, multifacético y clarificador a la vez; pero es que no podría ilustrarse de otra mejor manera la recepción del compositor de Salzburgo en el ámbito español. "Mozart en España. Estudios y recepción musical", dirigido por Paulino Capdepón y Juan José Pastor, es un libro que reflexiona desde diferentes ámbitos la integración de Mozart en la música y la cultura española. Con gran acierto se suceden cada uno de los diez capítulos de esta novedad editorial sin precedentes en la historiografía musical, en la que participan importantes especialistas del ámbito mozartiano.

La monografía comienza con la intervención de la catedrática de la Universidad de Heidelberg, Silke Leopold, con el capítulo titulado "Colorido local español en el teatro musical vienés: Mozart y el fandango". El capítulo plantea primeramente una interesante reflexión histórica sobre el colorido local en las artes y la música, como el caso de la ópera cómica que utilizaba lo extraño o diferente con la intención de ridiculizar, o la apropiación de Luis XIV de las danzas regionales de su país con finalidades centralistas y absolutistas. 


\section{RESEÑAS DE LIBROS}

Más adelante se expone el interesante uso que Gluck hace de un fandango español en el ballet Don Juan ou Le festin de Pierre (1761) con la intención de dotar de colorido local a una escena festiva de baile y banquete. Para el público vienés de esa época el fandango era algo desconocido, novedoso y exótico. Mozart citó el fandango de Gluck en Le nozze di Figaro (1786), pero no solamente con la intención de dotar de colorido español a una escena operística, sino también como plataforma musical para construir un pasaje del argumento.

El segundo capítulo del libro, "Cosi fan tutte. El manuscrito de la versión barcelonesa (1798)", elaborado por Laura Pallàs, profesora de la Escuela Superior de Música de Cataluña, es un interesante estudio codicológico del manuscrito de la ópera mozartiana conservado en la Biblioteca de Cataluña con el topográfico M 6915. Descubierta en el año 2010, sería la partitura que se utilizaría para el estreno de esta ópera en España con motivo de la celebración onomástica del rey Carlos IV en noviembre de 1798 en el Teatro de Barcelona. El estudio de esta fuente desvela, entre otras cosas, las múltiples modificaciones que se hacen a la ópera de Mozart en el estreno español y el probado origen vienés de la copia manuscrita.

"La recepción de la música de Mozart en España desde finales del siglo XVIII hasta 1832" es la aportación de Paulino Capdepón, profesor de la Universidad de CastillaLa Mancha, para el tercer capítulo del libro. Sin duda se trata de un estudio imprescindible para entender la presencia de Mozart en España en vida del compositor y durante las décadas inmediatamente posteriores a su muerte. Comienza el capítulo con una revisión del estado de la cuestión sobre la investigación de la recepción mozartiana en el ámbito español y la confección de un interesante contexto histórico. A continuación se expone la temprana recepción de Mozart en España a través de diversa documentación de la época; por ejemplo, las partituras conservadas en el Archivo del Palacio Real de Madrid y la Biblioteca Nacional de España, fuentes hemerográficas que revelan la oferta comercial de partituras del compositor salzburgués y la existencia de la modalidad de venta de copias manuscritas confeccionadas por compositores españoles, y el descubrimiento del manuscrito de la primera ópera de Mozart interpretada en España que actualmente se conserva en la Biblioteca de Cataluña. Sigue el estudio de la recepción de Mozart a comienzos de siglo XIX con el análisis del estreno de Le nozze di Figaro y el Requiem en Madrid, el primero en 1802 y el segundo hacia 1805-1806. Finalmente el capítulo concluye con el estudio pormenorizado del interesante papel del cantante y compositor español Manuel García en la difusión internacional de las óperas de Mozart. Son de gran valor los apéndices documentales que se incluyen al final del capítulo, que consisten en críticas musicales de las interpretaciones españolas de la música mozartiana y una lista de fuentes musicales de este compositor conservadas en la Biblioteca Nacional.

El cuarto capítulo lleva por título "La importancia de la microestructura en Die Zauberflöte de W.A. Mozart: reflexión analítica sobre Das Klinget so Herrlich -o el encantamiento de Monastos- en las Variaciones de Fernando Sor y la Fantasía de Pablo de Sarasate". El texto, elaborado por José Luis de la Fuente, profesor de la Universidad de Castilla-La Mancha, se centra en analizar y discutir la importancia del concepto de 


\section{RESEÑAS DE LIBROS}

expresión en Mozart y su relación con la tonalidad como limitación expresiva y las ideas de forma y microestructura. A partir de estos supuestos, el autor del capítulo se centra en el análisis de las variaciones que los compositores españoles Fernando Sor y Pablo Sarasate hacen de un tema de Mozart.

Francisco Manuel López, profesor de la Universidad Internacional Isabel I, escribe la quinta parte de este libro: "La recepción de la obra lírica de Mozart en Madrid en la segunda mitad del siglo XIX”. El capítulo se centra en el estudio de la interpretación de la ópera Don Giovanni en Madrid en la década de los 60 del siglo XIX. Particular interés tiene el análisis que se hace de las modificaciones realizadas a la ópera de Mozart con el fin de "romantizarla" para adaptarla al gusto del público madrileño.

"Presencia y recepción de Mozart en España en el primer tercio del siglo XX", es el capítulo elaborado por José María García, catedrático de la Universidad de Salamanca. En el texto se presenta una aproximación al estudio de la recepción que las ciudades de Madrid y Barcelona hacen de la música de Mozart en las primeras décadas del siglo XX. Es muy interesante la contextualización previa que realiza de la "actualidad" del compositor de Salzburgo en la música y la sociedad europeas a comienzos de siglo, afirmando por ejemplo, que hubo un redescubrimiento de Mozart a raíz del rechazo de las tendencias estéticas románticas. En España, la consolidación del repertorio sinfónico y camerístico mozartiano es posible gracias a las sociedades y asociaciones de música y la fundación de diversas orquestas y grupos instrumentales. Sin embargo, en este periodo las óperas de Mozart no tienen la misma suerte que su música orquestal y camerística debido a que el gusto del público estaba del lado del belcantismo italiano y Wagner. Con gran minuciosidad el profesor José María García recrea el mundo mozartiano en la España de comienzos de siglo aportando citas de críticos musicales de la época y un detallado estudio sobre el repertorio interpretado por las principales agrupaciones instrumentales.

Juan José Pastor, profesor de la Universidad de Castilla-La Mancha, escribe el séptimo capítulo del libro, lleva por título "Imbécil, heterodoxo y sentimental: lecturas marginales sobre Mozart en la segunda mitad del siglo XIX y principios del XX”. Aquí se plantea la influencia de la figura de Mozart más allá de la música, concretamente en los ámbitos estéticos, pedagógicos, filosóficos, morales, psicológicos y espiritistas. El profesor Pastor, con un discurso acertado y en ocasiones irónico, nos transporta a través de la construcción de la concepción romántica del genio mozartiano en la prensa literaria de la época, de los mitos y la concepción sobrenatural de Mozart a través de manuales pseudocientíficos y paranormales, de la genialidad y lo imbécil que hay en el compositor salzburgués a través de libros psicológicos, y de la utilización de la figura de Mozart como un ejemplo para la educación de la infancia en el ambiente moralista católico.

El octavo capítulo del libro es "Mozart y el franquismo: una mirada desde el arte cinematográfico", escrito por Virginia Sánchez Rodríguez, profesora de la Universidad Alfonso X el Sabio. El capítulo comienza con un oportuno estudio introductorio del papel de las artes y la música en el régimen franquista. Expone que la sociedad española de esa época no apreciaba mucho las nuevas corrientes estéticas de la música ya que tanto la 


\section{RESEÑAS DE LIBROS}

Administración como el público en general preferían la de tradición clásica y aquella que se alineaba con los modelos nacionalistas. La enseñanza musical en la educación pública era tarea de los miembros del Frente de Juventudes, quienes buscaban inculcar el espíritu nacional a los niños a través de la música. El cine, una de las artes preferidas por el dictador, tuvo un importante apoyo por parte del régimen, pues le servía como medio de propaganda política. La música tuvo cierto protagonismo en este proceso, ya que era un medio de difusión del folklore español. La parte fundamental del capítulo de Virginia Sánchez es el análisis de dos casos contrastantes del uso de la música en el cine del franquismo con las composiciones de Mozart como protagonistas. El primero de ellos es El pequeño coronel (Antonio del Amo, 1960), en donde la música de Mozart es utilizada como contraste entre la tradición clásica de las élites conservadoras y la música de tradición folklórica. El segundo caso es el de Viridiana (Luis Buñuel, 1961), película de corriente realista y costumbrista que muestra la realidad social de la época con el propósito de hacer una crítica del régimen. El Requiem de Mozart suena en este film con una intención semántica e ideológica.

"Mozart en España..." concluye con dos capítulos, que si bien no están directamente relacionados con la temática de la monografía, aportan un valor añadido al libro especialmente por haber sido elaborados por importantes académicos del ámbito musicológico internacional. Uno de ellos es Costantín Floros, profesor de la Universidad de Hamburgo, quien en el capítulo "Tragedia y comedia en las óperas maestras de Mozart", realiza una profunda e interesante reflexión de la universalidad dramática de Mozart al haber cultivado todos los géneros operísticos de su tiempo. Finalmente, la intervención de Pierluigi Petrobelli, quien fuera catedrático de la Universidad La Sapienza de Roma, lleva por título “¿Por qué Don Giovanni va al infierno?”. El capítulo hace una nueva lectura de la interpretación dramática y musical del personaje principal de esta gran ópera mozartiana.

Después de haber comentado los aspectos más sobresalientes de cada uno de los diez capítulos de esta novedad editorial, podemos decir que sin duda alguna nos vemos obligados a replantearnos la idea que teníamos de la influencia de Mozart en el ámbito español, que hasta ahora creíamos muy limitada. Si bien, Mozart no tuvo la misma influencia y aceptación que algunos compositores contemporáneos y posteriores a él (caso concreto de Haydn y los compositores operísticos italianos y Wagner), sí podemos afirmar que el compositor salzburgués siempre estuvo presente de alguna manera en la música y la cultura española.

Fecha de recepción: 17/10/2016

Fecha de aceptación: 18/11/2016

Rigoberto Macías Peraza Conservatorio Superior de Música de Castilla-La Mancha 